Bulletin of the Transilvania University of Braşov • Vol 13(62), No. 2 - 2020

Series III: Mathematics, Informatics, Physics, 479-508

https://doi.org/10.31926/but.mif.2020.13.62.2.9

\title{
A NOVEL EPIDEMIC MODEL TO ANALYZE AND CONTROL THE CHAOTIC BEHAVIOR OF COVID-19 OUTBREAK
}

\author{
R. CHUGH $^{1}$, A. KUMAR ${ }^{2}$ and S. KUMARI ${ }^{*, 3}$
}

\begin{abstract}
The coronavirus disease 2019 (COVID-19) has been spread all over the world. There are more than 43.14 million COVID-19 confirmed cases and over 1.15 million deaths reported worldwide till October 26, 2020. As the proper treatment/vaccine is not available, most of the countries are relying on various preventive measures to check the spread of epidemic. The aim of this article is to analyze the impact of corona preventive measures on the spread of COVID-19 by employing a novel epidemic model. Moreover, time series and bifurcation analysis techniques have been used to estimate this impact. To prove the validity of our model, we apply our model on highly affected countries such as China, Italy, USA, UK and India. Our findings might be very useful tool for decision holders and policy makers to take the right decisions in a timely way to control the outbreak of COVID-19, knowing the uncertainties about the coronovirus disease. We show a good agreement between the reported data and the estimations given by our model.
\end{abstract}

Key words: Coronavirus disease 2019, corona preventive measures, novel epidemic model, time series plot, bifurcation diagram.

Mathematical Subject Classification: 37G15, 37M10, 37C25, 37C35.

\section{Introduction}

Coronavirus disease 2019 (COVID-19) is an acute respiratory infectious disease caused by the novel coronavirus (SARS-CoV-2) $[23,33]$. It is highly infectious and is spreading at a rapid pace worldwide. It was first reported in Hubei (China)

\footnotetext{
${ }^{1}$ Department of Mathematics, Maharshi Dayanand University, Rohtak-124001, Haryana, India. e-mail: chugh.r1@gmail.com

${ }^{2}$ Department of Mathematics, Maharshi Dayanand University, Rohtak-124001, Haryana, India.e-mail: amit.math2018@gmail.com

$3 *$ Corresponding author, Department of Mathematics, Government College for Girls Sector14, Gurugram 122001, Haryana, India. e-mail: tanwarsudesh10@gmail.com
} 
and has been spread over more than 185 countries so far [10]. The World Health Organization (WHO) affirmed this outbreak as a Public Health Emergency of International Concern on January 30, 2020 and declared it as a pandemic on March 11, $2020[22,25]$. As on May 15, 2020 a total of 4.3 million confirmed cases of COVID-19 and over 297,000 deaths [21] have been reported worldwide. Among major affected countries including UK, Italy, Spain, France etc. United States tops the chart with more than 1.3 million confirmed infected people and with over 82,000 deaths [21] till May 16, 2020. This global pandemic has also affected a wide range of the international economic and trade activities, medical supplies and other global value chains, tourism and hospitality services, consumer electronics, and financial markets to energy, transportation, food, and a range of social activities. It is estimated that COVID-19 could cut down the global economy growth by as much as $2 \%$ per month if current situation persists. This health and economic crisis could negatively influence the economies of developing countries that are constrained by limited financial resources and where health systems could quickly become overloaded. Hence, COVID-19 could be seen as a turning point moment in the history of world.

Coronaviruses are a large group of viruses distributed broadly among humans, other mammals, and birds, and cause respiratory, enteric, hepatic, and neurologic diseases. Coronaviruses have caused two large-scale pandemics in the past two decades, namely, Severe Acute Respiratory Syndrome (SARS) [24] and Middle East Respiratory Syndrome (MERS) [37]. The novel coronavirus SARS-CoV-2 (similar to the one that caused the SARS outbreak), initially called 2019-nCoV, is responsible for the current pandemics COVID-19. The significant explanation for this pandemic is that it spreads quickly among individuals who are in close contact to each other. To contain COVID19 spread many countries have instituted several corona preventive measures such as lockdown, social distancing, self-quarantine and self-isolation, closure of schools and shopping malls, rigorous hand washing, respiratory etiquette, use of face masks etc. These mitigation efforts are made to minimize the morbidity and associated mortality, to avoid an epidemic peak that overwhelms healthcare services, to keep the effects on economy with a manageable level and to flatten the epidemic curve to wait for development vaccine/antiviral drug therapies. Since there is no specific treatment for COVID-19 and no vaccine to prevent it, it is need to develop the prediction models for evaluation of the preventive measures on this pandemic.

The research and analysis of infectious disease prediction models play an important role in understanding the mechanism of disease spreading. Recently, the epidemic models have gained a lot of attention as they are very helpful in predicting, assessing, and controlling/reducing the potential harm of infectious disease. The researchers have developed a considerable interest in developing the epidemic models to estimate the transmissibility and dynamic of the transmission of the epidemic. In the first quarter of 2020, a lot of efforts have been made to estimate the basic reproduction number $R_{0}$ and to make prediction about the future trajectory of the coronavirus disease 2019 (COVID-2019) outbreak [1, 13, 15, 34, 38, 40, 41]. The most of prior researchers used the simple exponential growth models and 
they focused on the early growing process of the disease [11, 28, 36, 39]. On the other hand, there are also many researchers who argue that the number of infected people follows a trajectory which is different from simple exponential growth models $[4,5,27,35,40]$. Thus, COVID-19 has very complex transmission process and therefore can be studied with the help of nonlinear dynamical systems. The infectious disease has the property of chaos and oscillation $[2,3,12,17]$.

In nature, chaos is a nonlinear phenomena of nonlinear dynamical systems which changes over time based on its current situation, remains unpredictable, aperiodic and shows extreme sensitive dependence on the initial conditions $[14,16]$. The population growth model is a nonlinear chaotic dynamical system, originally due to P.F. Verhulst in 1945 [29] given by the equation

$$
f\left(x_{n}\right)=x_{n+1}=\lambda x_{n}\left(1-x_{n}\right), n=0,1,2, \ldots,
$$

where $x_{n} \in[0,1]$. It represents the population at any time $n$, where $\lambda$ is a control parameter indicating the rate of population growth [16]. He verified the calculations results obtained from his model by comparing these with the real population data of France, Belgium, Essex and Russia [30]. This model has been successfully applied to delineate the prior epidemics [6-8,31,32]. Similar to the growth of population, any infectious disease develops. This motivates us to formulate and employ a novel epidemic model to study the dynamics of COVID-19 which is a nonlinear dynamical system. In the present paper, we employ novel epidemic model to quantify the potentiality of corona preventive measures to control COVID-19 without detailed microscopic foundations. Our approach is advantageous since it allows the simple calibrations to the empirical reported data and thus provides transparent interpretations. This study can offer a straightforward insight about the status of COVID-19 epidemics and the future outbreaks.

\section{Mathematical formation of novel epidemic model}

In order to analyze the factors that affect and control the spread of COVID-19, it would be very useful to study the dynamics of the epidemic and therefore, we formulate a novel epidemic model by the relation:

$$
f\left(x_{n}\right)=x_{n+1}=\frac{1}{\mu} x_{n}\left(1-x_{n}\right), n=0,1,2, \ldots,
$$

where

- $x_{n} \in[0,1]$ is the total number of people infected from COVID-19 in $n$ number of days.

- the nonlinear parameter $\mu \in[0,1]$ is used to represent the corona preventive (mitigation) measures (in percentage) adopted by a government to mitigate the coronavirus disease. These measures include: (1) lockdown (2) social distancing (3) self-quarantine and self-isolation (4) ban on mass gatherings 
(5) isolation of households, towns, or cities (6) rigorous hand washing (7) respiratory etiquette (8) use of face masks etc.

The model 2 is based on population model logistic function which describes the dynamics of population whereas our model shows how coronavirus disease develops and spread rapidly. We are studying dynamics of COVID-19 with the help of this model because it maps the infectious population at any time step to its value at the next time step. Moreover, it is an attempt to find out the measures so that coronavirus disease is controlled. Now, we use the Model 2 to calculate the evolution of coronavirus disease by starting with some initial infectious population $x_{0}$ (between 0 and 1) and try to estimate the maximum value of $\mu$ to which the disease can be mitigated in such a way that the system is remain free from coronavirus disease. Using Matlab software, we iterate the Model 2 again and again to analyze the dynamics of COVID-19 and obtain the successive infected population $x_{1}, x_{2}, x_{3}$ and so on.

\section{Description and Analysis of the Model}

This section deals with the analysis of Model 2 that provides an essential information, what impact of corona preventive measures have on COVID-19 outbreak and it suggests a method to control the extent spreading of coronavirus disease. Our model defines the dynamics of corona infectious population: here variable $x$ and parameter $\mu$ are the percentage measures of the size of corona infected peoples and corona preventive measures respectively. $\mu=0$ (i.e., $0 \%)$ indicates extinction of corona preventive measures while $\mu=1$ (i.e., 100\%) represents the maximum possible implementation of mitigation measures. Similarly, $x=0$ demonstrates that there is no corona infected people, i.e., system (country or world) is free from coronavirus disease, whereas increasing value of $x$ towards 1 represents that cases of infected persons are increasing drastically. Thus, the size of infected people depends on the size of corona mitigation measures adopted by government at any given time. If the size of corona mitigation measures (in percentage) are set too low, the size of infected persons will increase abruptly. More than $75 \%$ implementation of corona preventive measures might settle the system toward a system which is free from coronavirus disease over time.

\subsection{Time seris analysis of the model}

We start our Model 2 by assuming that the size of infected peoples is 0.5 , i.e., $50 \%$ peoples are infected from coronavirus disease and the model is set up to demonstrates corona infected peoples between 0 (extinction) and 1 (the maximum population). To analyze our model, we depict the results for 50 number of days by iterating the model upto 50 times for different values of parameter $\mu$ of corona mitigation measures, i.e., for $\mu=0.15$ (15\%), $\mu=0.285(28.5 \%), \mu=$ $0.32(32 \%), \mu=0.45$ (45\%), $\mu=0.50$ (50\%), $\mu=0.75$ (75\%) and $\mu=1(100 \%)$ in the following table: 


\begin{tabular}{|l|l|l|l|l|l|l|l|}
\hline & $\mu=0.15$ & $\mu=0.285$ & $\mu=0.32$ & $\mu=0.45$ & $\mu=0.50$ & $\mu=0.75$ & $\mu=1$ \\
\hline 0 & 0.5 & 0.5 & 0.5 & 0.5 & 0.5 & 0.5 & 0.5 \\
\hline 1 & 1.6666 & 0.8772 & 0.7813 & 0.5556 & 0.5000 & 0.3333 & 0.25 \\
\hline 2 & -7.4074 & 0.3780 & 0.5341 & 0.5487 & 0.5000 & 0.2963 & 0.1875 \\
\hline 3 & -415.1806 & 0.8249 & 0.7777 & 0.5503 & 0.5000 & 0.2780 & 0.1523 \\
\hline 4 & -1151934.100 & 0.5067 & 0.54039 & 0.5499 & 0.5000 & 0.2676 & 0.1291 \\
\hline 5 & - & 0.87770 & 0.7762 & 0.5500 & 0.5000 & 0.2613 & 0.1124 \\
\hline 6 & - & 0.3784 & 0.5429 & 0.5499 & 0.5000 & 0.2573 & 0.0998 \\
\hline 7 & - & 0.8253 & 0.7755 & 0.5500 & 0.5000 & 0.2548 & 0.0898 \\
\hline- & - & - & - & - & - & - & - \\
\hline- & - & - & - & - & - & - & - \\
\hline- & - & - & - & - & - & - & - \\
\hline 46 & undefined & 0.3783 & 0.5451 & 0.5500 & 0.5000 & 0.2500 & 0.0193 \\
\hline 47 & undefined & 0.8252 & 0.7749 & 0.5500 & 0.5000 & 0.2500 & 0.0190 \\
\hline 48 & undefined & 0.5060 & 0.5451 & 0.5500 & 0.5000 & 0.2500 & 0.0186 \\
\hline 49 & undefined & 0.8770 & 0.7748 & 0.5500 & 0.5000 & 0.2500 & 0.0182 \\
\hline 50 & undefined & 0.3783 & 0.5451 & 0.5500 & 0.5000 & 0.2500 & 0.0179 \\
\hline
\end{tabular}

Table 1: Inverse relation between the corona preventive measures $(\mu)$ and the infected population $\left(x_{n}\right)$

In Table 1, columns represent the parameter $\mu$ while size of infected people have been represented by rows. From the first column of the table, it is clear that for $\mu=0.15$ the confirmed cases cross 1 only in 1 day, in this case the system cannot be defined as $x_{n} \notin[0,1]$ but we have considered $x_{n}$ in $[0,1]$. Further, the size of infected peoples fluctuates between four values for $\mu=0.285$ as shown by second column. For $\mu=0.32$, the size of infected peoples becomes stable and it fluctuates between two values (see column 3). Moreover, for $\mu=0.45,0.5,0.75$, the size of confirmed cases becomes stable and fixed to the values $0.5500,0.5000$ and 2500 on each day respectively. It is noticeable that the pandemic COVID19 approaches toward zero when 100\% $(\mu=1)$ stringent measures of corona mitigation are adopted by the government of a country as shown in the last column.

Now, we visualize the results obtained in Table 1 by a time series plot. In Fig. 1 , we demonstrate the impact of corona preventive measures $(\mu)$ on the size of coronavirus infected population. We consider number of days on the $\mathrm{x}$-axis while size of infected patients has been represented on y-axis. 


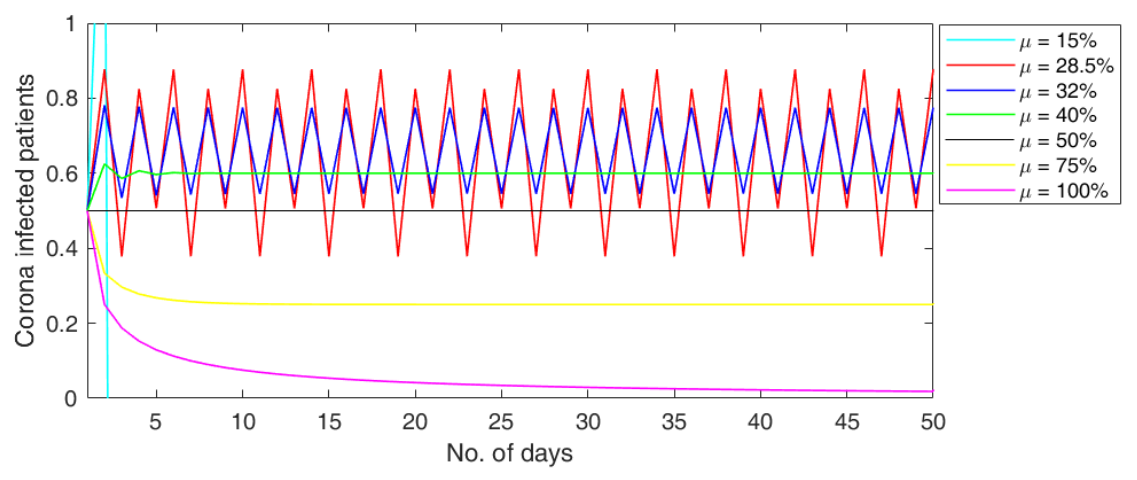

Figure1: Timeseries plot to analyze the effect of corona preventive measures on the size of infectious peoples

One can easily observed from the Fig. 1, how the size of corona infected patients varies over days by adopting different percentages of parameter $\mu$. The cyan line represents $15 \%$ implementation of corona preventive measures and it quickly crosses the value 1 which is maximum possible population. The whole population is infected from COVID-19. At this stage we see the onset of the chaos. Thus, system cannot be defined for this value of $\mu$. The cases of corona infected patients fluctuates between two values for $\mu=28.5 \%$ as shown by red line. The blue line demonstrates that the confirmed cases remain stable and oscillate between two values when $32 \%$ mitigation measures have been adopted. Further, the size of the patients can be made stable and fixed by taking $\mu=44 \%$ and $\mu=50 \%$ as represented by green and violet lines respectively. While the yellow line for $\mu=75 \%$ seems to be slowly decreasing and converging toward a fixed value. The magenta line is very interesting which explains that if $100 \%$ mitigation measures are adopted then the corona positive cases decrease rapidly and converges toward zero.

Remark 1. From above discussion, it is observed that corona preventive measures influence very much the spread of the COVID-19 epidemic. By adopting higher percentage of corona preventive measures, the disease coronavirus can be controlled timely. Table 1 and Figure 1 shows that adoption of stringent measures rapidly reduces the number of corona infected patients.

\subsection{Bifurcation Analysis of the Model}

This section deals with the bifurcation analysis of the Model 2 which validates the results obtained in Subsection 3.1. The bifurcation diagrams are the tools generally used to classify the dynamical systems in nonlinear regimes. Bifurcation diagrams show an abrupt change which occur in the asymptotic solution of a dynamical system. Here, for some initial values of $x_{n} \in[0,1]$ the behavior of corona infected population have been studied. The role of corona preventive measures to control the outbreak of COVID-19 has also been observed. This experimental ap- 
proach shows that the corona mitigation measures affect the dynamical behavior of infectious people very much. The control parameter $\mu$ is taken on horizontal line and infected population are on vertical line.

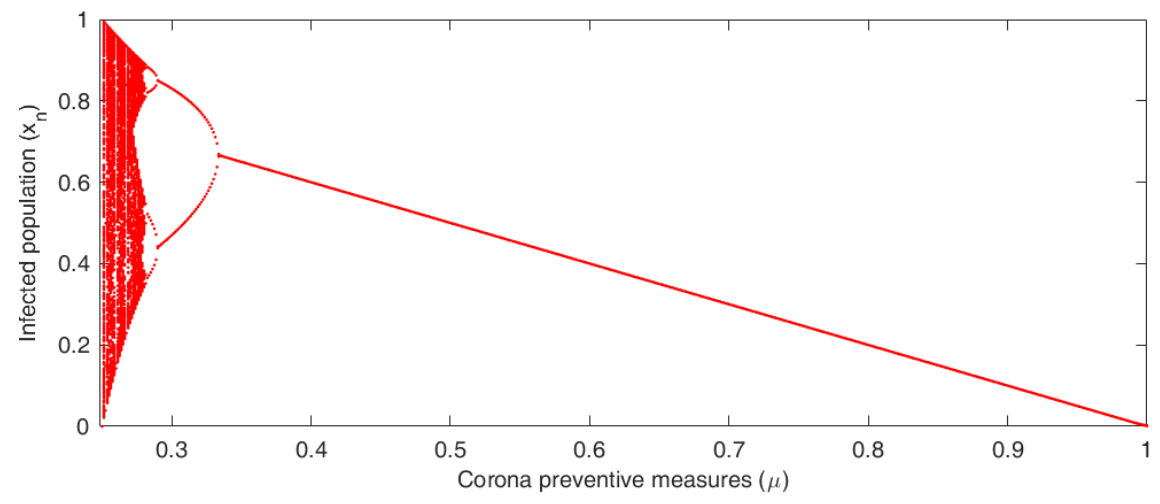

Figure 2: Bifurcation plot tostudy the dynamical behavior of infectious population

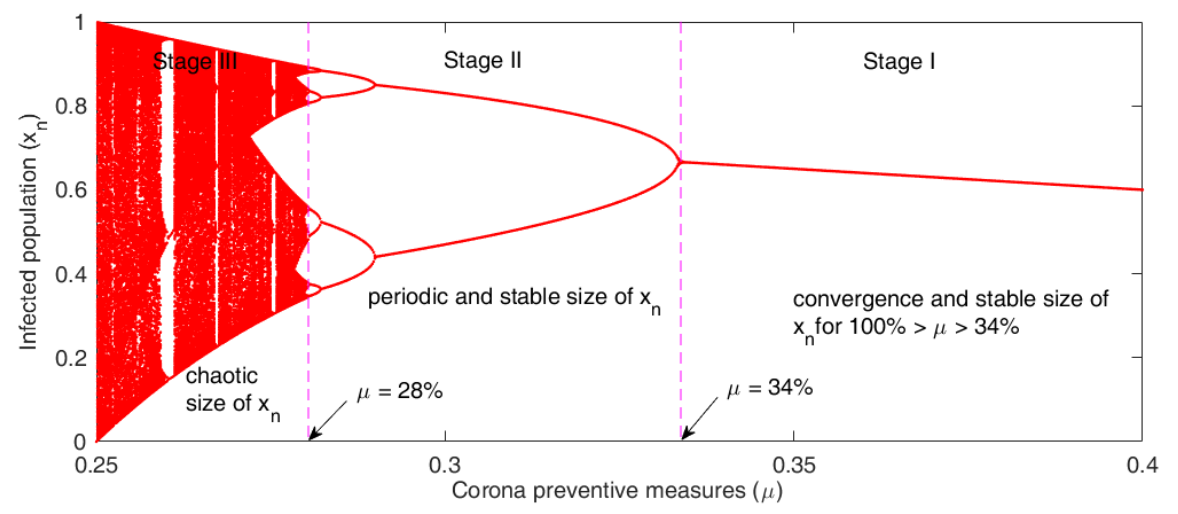

Figure 3: Magnified bifurcation plot tostudy the dynamical behavior of infectious population

The Fig. 2 depicts the entire bifurcation plot of Model 2 for $0.2 \leq \mu \leq 1$. We notice that the infected population converges to zero for $\mu=1$. In Fig. 3, we analyze the beauty of chaos of our model by magnifying the bifurcation plot for $0.2 \leq \mu \leq 1$. From Fig. 3, we notice that when we decrease the value of $\mu$, the cases of infected population start to increase. The whole dynamical behavior of infected population is bifurcated into three stages (separated by dotted magenta lines) according to the size of infected population. As we decrease the value of $\mu$ from $\mu=100 \%$ to $\mu=34 \%$ the size of infected peoples increases slowly and the system remains stable (see Stage I). For $34 \% \geq \mu \geq 28 \%$, infected patients increase periodically as represented by Stage II. Up to this stage, the system remains stable, i.e., the government of a country can handle the corona disease. Stage III shows that when we decrease the value of $\mu$ through $\mu<28 \%$, the bifurcations ramp up and the chaos starts to occur in the system due to abruptly 
increased corona infected population. This is known as the period-doubling path to chaos. In this situation, government remains unable to diminish deaths from COVID-19. This demonstrates the chaotic behavior of COVID-19. This model follows very simple deterministic rules yet produces apparent randomness. This is chaos: deterministic and aperiodic. Thus the number of corona patients depends on mitigation preventive measures.

Remark 2. The bifurcation analysis describes that corona mitigation measures strongly affect the chaotic dynamics of COVID-19. The chaotic behavior of COVID19 (worst condition) can be controlled by applying stringent mitigation measures appropriately.

\section{Analysis of COVID-19 outbreak to substantiation the results of our epidemic model}

Next, to validate our results obtained in Section 3, we study the specific cases of those countries which are going through extent outbreak of this virus: China, Italy, USA, UK, India and compare the figure of infected population of these countries with the results of Model 2. Our study analyzes the impact of the stringent corona preventive measures at the aggregate level on COVID-19 pandemics and epidemics in these countries till May 15, 2020. A suitable identification of the model parameter $\mu$ may be of interest for the application of our model to other countries/territories.

\subsection{Analysis of COVID-19 outbreak in China}

In December 2019, several cases of acute respiratory tract infection were first reported in Hubei province in China. An increasing number of patients with pneumonia of unknown etiology alarmed the local hospital in Wuhan city. Most of the cases found initially were originated from a common source, the Huanan wholesale seafood market, and several researchers suggested the animal bat as a potential reservoir of SARS-CoV-2 [9,26]. China informed the outbreak to the WHO on December 31, 2019 and on next day the Huanan sea food market in Wuhan was closed. The number of cases started increasing exponentially, and the migration of people in large numbers on Chinese New Year further fuelled the epidemic. The Cases in other areas of China and other neighbour countries (Thailand, Japan and South Korea) were identified in the people who had returned from Wuhan. On January 20, the transmission was also confirmed in the healthcare workers who were involved in caring for patients. The day wise total number of cases has been

presented in the Table 2, the day one was considered on 1/22/2020 [18]. By using the data given in Table 2 a figure is obtained to visualize the outbreak graphically (Fig. 4). 


\begin{tabular}{|l|l|l|l|}
\hline Date & No. of Days & Total Confirmed Cases Total Deaths \\
\hline $1 / 22 / 2020$ & 1 & 433 & 9 \\
\hline $1 / 29 / 2020$ & 7 & 5995 & 132 \\
\hline $2 / 5 / 2020$ & 14 & 24363 & 491 \\
\hline $2 / 12 / 2020$ & 21 & 44730 & 1114 \\
\hline $2 / 19 / 2020$ & 28 & 74279 & 2006 \\
\hline $2 / 26 / 2020$ & 35 & 78190 & 2718 \\
\hline $3 / 4 / 2020$ & 42 & 80422 & 2984 \\
\hline $3 / 11 / 2020$ & 49 & 80955 & 3162 \\
\hline $3 / 18 / 2020$ & 56 & 81174 & 3242 \\
\hline $3 / 25 / 2020$ & 63 & 81869 & 3287 \\
\hline $4 / 1 / 2020$ & 70 & 82638 & 3321 \\
\hline $4 / 8 / 2020$ & 77 & 83161 & 3342 \\
\hline $4 / 15 / 2020$ & 84 & 83747 & 3352 \\
\hline $4 / 22 / 2020$ & 91 & 84288 & 4642 \\
\hline $4 / 29 / 2020$ & 98 & 84369 & 4643 \\
\hline $5 / 6 / 2020$ & 105 & 84404 & 4643 \\
\hline $5 / 13 / 2020$ & 112 & 84458 & 4644 \\
\hline
\end{tabular}

Table 2: Total number of confirmed cases of COVID-19 and deaths in China

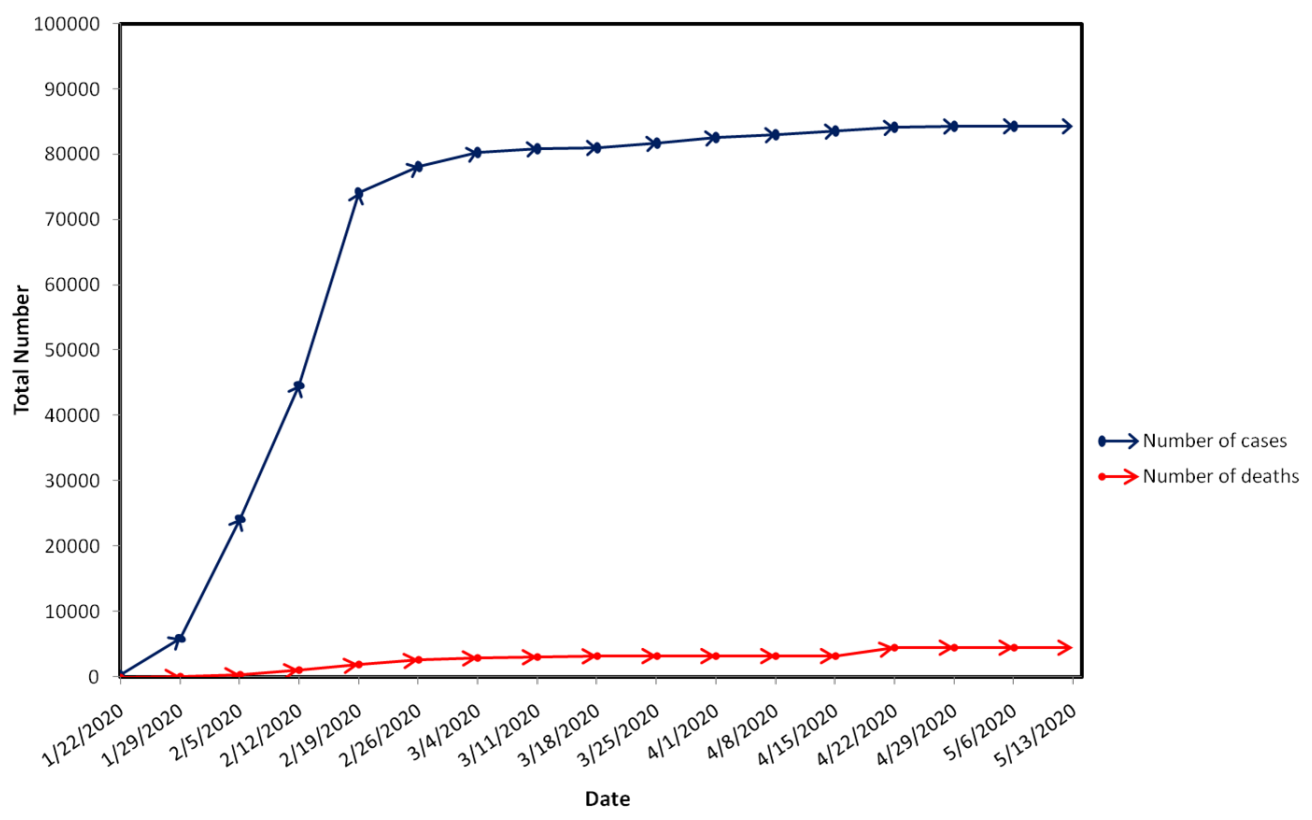

Figure 4: Reported cases of COVID-19 and deaths in China 
The Wuhan city was placed under lockdown by 23rd January putting 11 million population under constraints of coming in and going out from the region. The lockdown was extended to other cities of Hubei province in no time. The effects of lockdown could be observed after three weeks as there was a decline in the number of new cases (Fig.4). A total of 79,968 cases of COVID-19 and over 2873 deaths had been reported in the mainland China as of March 1. By March 6, the number of new cases declined to less than 100 broadly every day, down from thousands every day at the peak of the catastrophe. As the new cases per day kept declining and the epidemic outbreak remained at low level, on March 12 China declared that the COVID-19 peak is over. A dramatic decrease in new cases was reported after March 12 (as shown in Fig. 4) and the daily new cases in Wuhan city were dropped to single digit. The implementation of preventive measures was successful in Wuhan city as no new case was reported in more than one month as on May 10. From the Fig. 4, it can be deduced that the preventive measures played a significant role in flattening the curve.

\subsection{Analysis of COVID-19 outbreak in Italy}

In Italy, the very first two cases of COVID-19 were reported in Rome on January 31, 2020. The Italian government instantly declared a national emergency and suspended all the flights of China. On February 22, Prime Minister Conte declared a new decree, imposing quarantine of more than 50,000 people, in the Northern Italy. The pandemic spread quickly all over the country and many small towns were hit by the outbreak till February 23 as the total confirmed cases increased to 150. The day wise total number of cases has been presented in the Table 3, the day one was considered on 2/15/2020 [18]. By using the data given in Table 3, we obtain a figure to visualize the outbreak graphically (Fig. 5). 


\begin{tabular}{|l|l|l|l|}
\hline Date & No. of Days & Total Confirmed Cases Total Deaths \\
\hline $2 / 15 / 2020$ & 1 & 3 & 0 \\
\hline $2 / 20 / 2020$ & 5 & 3 & 0 \\
\hline $2 / 25 / 2020$ & 10 & 322 & 12 \\
\hline $3 / 1 / 2020$ & 15 & 1689 & 35 \\
\hline $3 / 6 / 2020$ & 20 & 4636 & 197 \\
\hline $3 / 11 / 2020$ & 25 & 12462 & 827 \\
\hline $3 / 16 / 2020$ & 30 & 27980 & 2158 \\
\hline $3 / 21 / 2020$ & 35 & 53578 & 4827 \\
\hline $3 / 26 / 2020$ & 40 & 74386 & 7505 \\
\hline $3 / 31 / 2020$ & 45 & 101739 & 11591 \\
\hline $4 / 5 / 2020$ & 50 & 124632 & 15362 \\
\hline $4 / 10 / 2020$ & 55 & 143626 & 18281 \\
\hline $4 / 15 / 2020$ & 60 & 162488 & 21069 \\
\hline $4 / 20 / 2020$ & 65 & 178972 & 23660 \\
\hline $4 / 25 / 2020$ & 70 & 192994 & 25969 \\
\hline $4 / 30 / 2020$ & 75 & 203591 & 27682 \\
\hline $5 / 5 / 2020$ & 80 & 211938 & 29079 \\
\hline $5 / 10 / 2020$ & 85 & 218268 & 305395 \\
\hline $5 / 15 / 2020$ & 90 & 223096 & 31368 \\
\hline
\end{tabular}

Table 3: Total number of confirmed cases of COVID-19 and deaths in Italy 


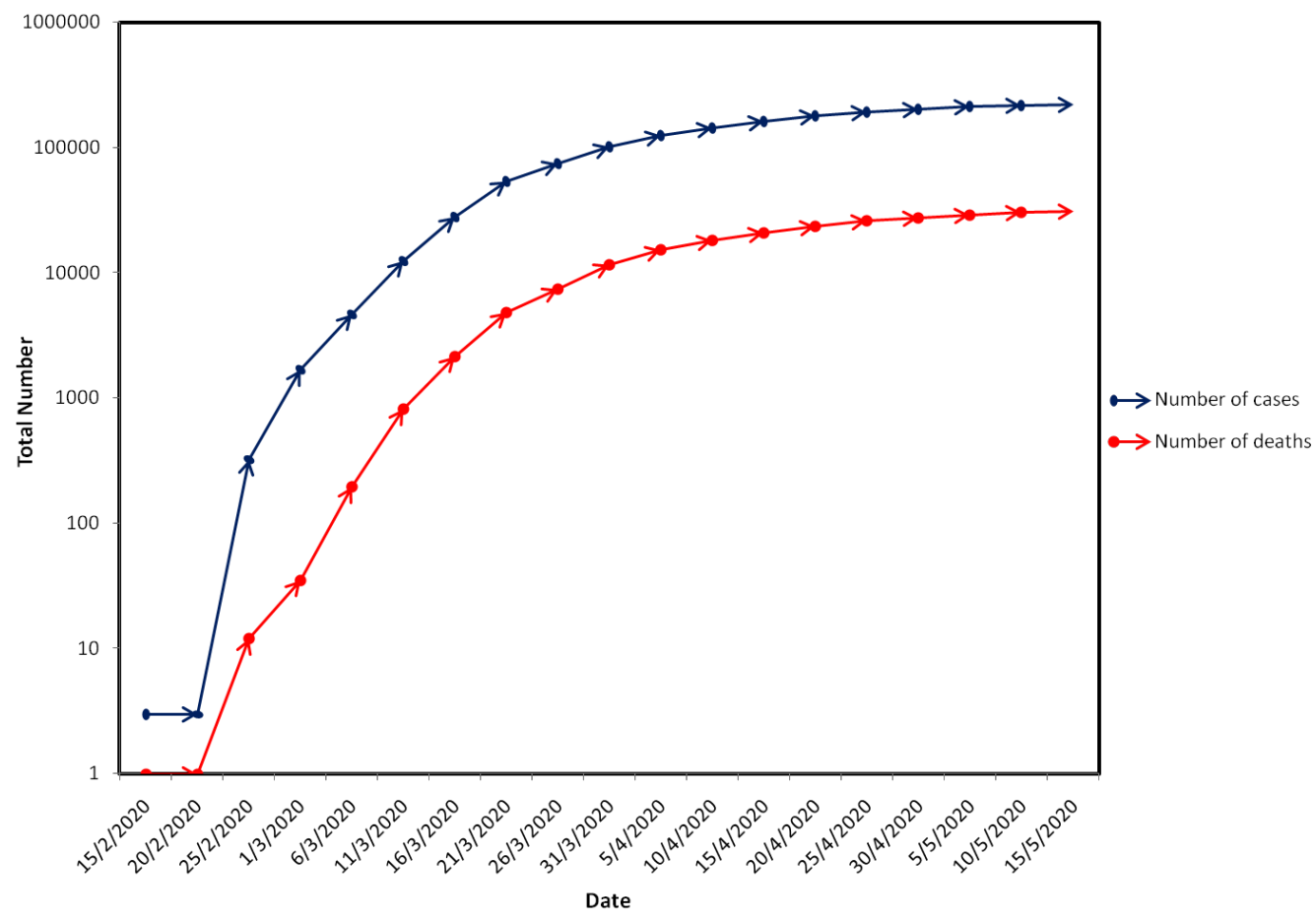

Figure 5: Reported cases of COVID-19 and deathsin Italy 
Italy reported over 3,000 cases and more than 100 deaths on March 4, and government closed the schools and universities. On March 9, all the sporting events in Italy were cancelled till at least 3 April, and the nationwide restrictions were announced, putting approximately 60 million people in lockdown. On 11 March, the total number of cases was exceeded 12,000, and the government declared a tightening of the lockdown, which included the closing of all commercial and retail businesses except the essential services. Within three weeks, a decline in the number of new cases was reported and new deaths per day were also less as shown in Fig. 5. On April 1, the government announced the extension of lockdown till 13 April, as the restrictive measures had started to generate the desired results. In early April, the lockdown was further extended till May 3 and all the Italian ports were closed till 31st July. On April 6, Italy reported the lowest number of new daily cases and lowest number of daily deaths in two and a half week. On April 20 , Italy recorded the first decline in the total number of active cases. It can be seen from the Fig. 5 that the epidemic outbreak was restrained effectively by im-

plementing the preventive measures/lockdown which further helped in flattening the epidemic curve.

\subsection{Analysis of COVID-19 outbreak in UK}

In the United Kingdom, the COVID-19 outbreak appeared in late January 2020. On February 6, Britain's third case tested positive, having travel history of Singapore, and who was later linked with 11 other cases, five of which were in the UK. The outbreak was spread gradually in the beginning as on February 23, the total number of cases was 13 in UK. Cases of COVID-19 began to surge in March as the number of cases surged past 100 and first death was reported on March 5 . On April 26, the number of recorded deaths took past 20,000 to 20,319, making the UK fifth country to pass the 20,000 mark along with the United States, Italy, Spain and France. On May 5, the number of people to die with coronavirus in the UK had reached 28,734, surpassing Italy to become the highest toll in Europe [20]. The day wise total number of cases has been presented in the Table 4, the day one was considered on 2/15/2020 [18]. By using the data given in Table 4, we visualize the outbreak graphically by Fig. 6 . 


\begin{tabular}{|l|l|l|l|}
\hline Date & No. of Days & Total Confirmed Cases Total Deaths \\
\hline $2 / 15 / 2020$ & 1 & 9 & 0 \\
\hline $2 / 20 / 2020$ & 5 & 9 & 0 \\
\hline $2 / 25 / 2020$ & 10 & 13 & 0 \\
\hline $3 / 1 / 2020$ & 15 & 36 & 0 \\
\hline $3 / 6 / 2020$ & 20 & 167 & 1 \\
\hline $3 / 11 / 2020$ & 25 & 460 & 6 \\
\hline $3 / 16 / 2020$ & 30 & 1547 & 55 \\
\hline $3 / 21 / 2020$ & 35 & 5018 & 233 \\
\hline $3 / 26 / 2020$ & 40 & 9533 & 463 \\
\hline $3 / 31 / 2020$ & 45 & 22145 & 1408 \\
\hline $4 / 5 / 2020$ & 50 & 41907 & 4313 \\
\hline $4 / 10 / 2020$ & 55 & 65081 & 7978 \\
\hline $4 / 15 / 2020$ & 60 & 93877 & 12107 \\
\hline $4 / 20 / 2020$ & 65 & 120071 & 16060 \\
\hline $4 / 25 / 2020$ & 70 & 143468 & 19506 \\
\hline $4 / 30 / 2020$ & 75 & 165225 & 26097 \\
\hline $5 / 5 / 2020$ & 80 & 194994 & 29427 \\
\hline $5 / 10 / 2020$ & 85 & 215264 & 31587 \\
\hline $5 / 15 / 2020$ & 90 & 233155 & 33614 \\
\hline
\end{tabular}

Table 4: Total number of confirmed cases of COVID-19 and deaths in UK 


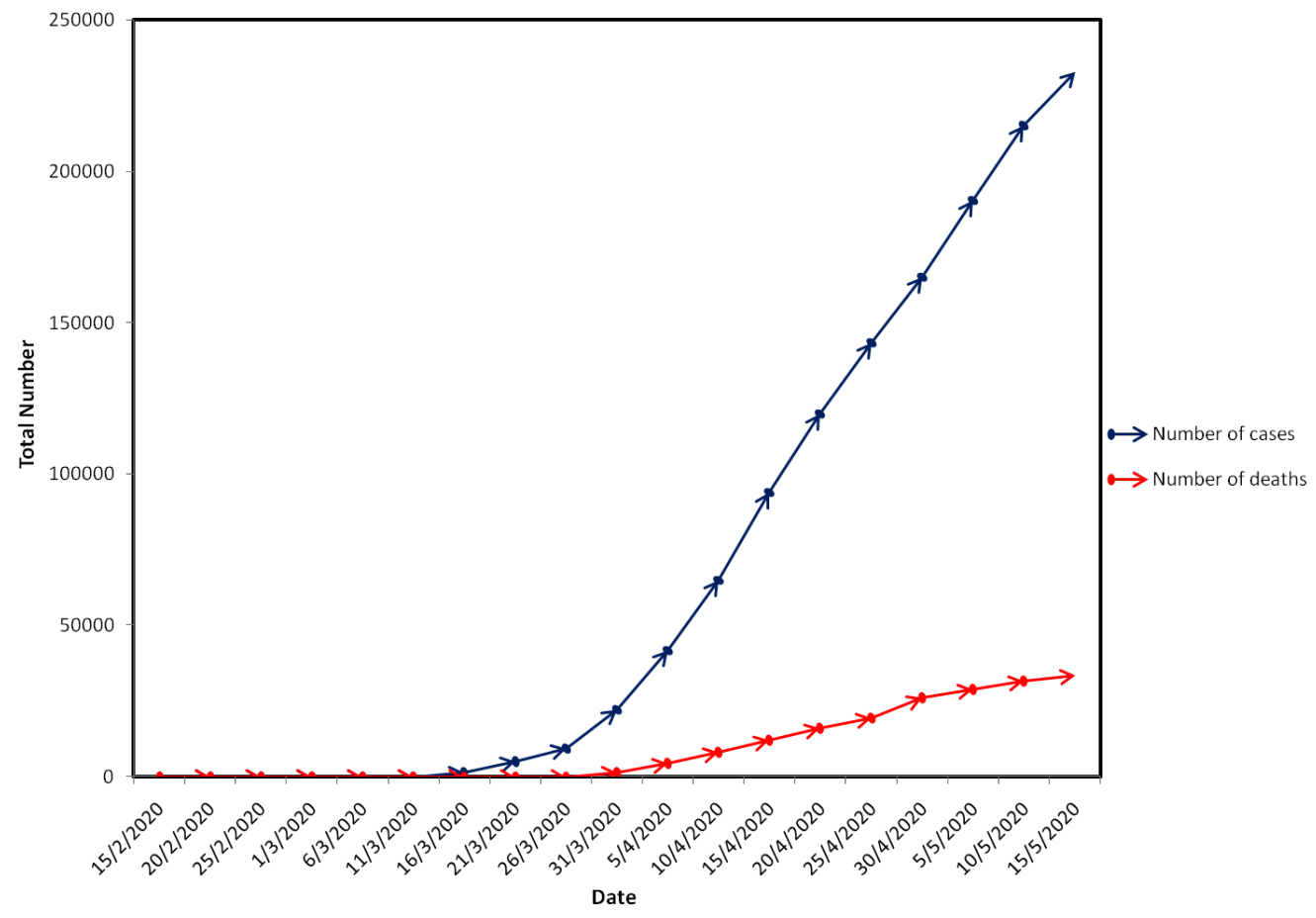

Figure 6: Reported cases of COVID-19 and deathsin UK 
Initially, Prime Minister Boris Johnson hesitated for the implementation of the lockdowns seen elsewhere in the Europe and mostly kept the UK open. In middle of March, the government announced an official advice for the self-isolation of pregnant women and elderly people (aged 70 years and above). On March 20, the

government closed all the schools, restaurants, pubs, indoor entertainment venues and leisure centres. On March 23, the UK government imposed a nationwide lockdown for three weeks on the whole population, however Johnson used the word "stay at home" instead of "lockdown" in his broadcast but the term was widely adopted in media. On April 15, Arlene Foster, the First Minister of Northern Ireland, announced the extension of lockdown in Northern Ireland till May 9. On day later The Foreign Secretary Dominic Raab announced an extension in countrywide lockdown measures for three weeks as the number of confirmed cases in the UK surpassed 100,000. The Fig. 6 shows that UK government did not take any action in the beginning and the epidemics spread at rapid pace. The preventive measures had started to yield positively after they were imposed in the later stage by the government.

\subsection{Analysis of COVID-19 in USA}

The United States announced its first confirmed case of COVID-19 on January 19, 2020. On 31 January, The Trump administration suspended the entry into the United States by any foreigner who has a travel history of China in the last 14 days, the immediate family members, permanent residents or American citizens were excluded. On February 26, the Centers for Disease Control and Prevention (CDC) reported the first case of suspected local transmission in United States. A case of COVID-19 was identified in California who had no travel history to an outbreak area, and no contact with anyone diagnosed with the virus. The US government did not take any strict preventive measure till this time. More cases of possible community transmission were reported soon after in Oregon, Washington and New York. The coronavirus was spread in all 50 states till March 17, as West Virginia reported the first COVID-19 case. Till March 20, New York City became the COVID-19 outbreak epicenter in US as more than 15,000 people were found positive, roughly half of the infections in the country. On March 27, the United States became the country hardest hit by the pandemic in the world, with more than 85,000 cases and over 12,00 deaths [19]. The total number of COVID-19 cases in the country stands at 1,361,522, with over 82,000 deaths [21] as on May 15. The day wise total number of cases has been presented in the Table 5, the day one was considered on 2/15/2020 [18]. By using the data given in Table 5, a figure is obtained to visualize the outbreak graphically (Fig. 7). 


\begin{tabular}{|l|l|l|l|}
\hline Date & No. of Days & Total Confirmed Cases Total Deaths \\
\hline $2 / 15 / 2020$ & 1 & 15 & 0 \\
\hline $2 / 20 / 2020$ & 5 & 15 & 0 \\
\hline $2 / 25 / 2020$ & 10 & 53 & 0 \\
\hline $3 / 1 / 2020$ & 15 & 62 & 0 \\
\hline $3 / 6 / 2020$ & 20 & 213 & 11 \\
\hline $3 / 11 / 2020$ & 25 & 696 & 25 \\
\hline $3 / 16 / 2020$ & 30 & 1714 & 41 \\
\hline $3 / 21 / 2020$ & 35 & 15219 & 201 \\
\hline $3 / 26 / 2020$ & 40 & 68334 & 991 \\
\hline $3 / 31 / 2020$ & 45 & 140640 & 2398 \\
\hline $4 / 5 / 2020$ & 50 & 273808 & 7020 \\
\hline $4 / 10 / 2020$ & 55 & 425889 & 14665 \\
\hline $4 / 15 / 2020$ & 60 & 578268 & 23476 \\
\hline $4 / 20 / 2020$ & 65 & 723605 & 34203 \\
\hline $4 / 25 / 2020$ & 70 & 860772 & 44053 \\
\hline $4 / 30 / 2020$ & 75 & 1003974 & 52428 \\
\hline $5 / 5 / 2020$ & 80 & 1154985 & 61906 \\
\hline $5 / 10 / 2020$ & 85 & 1245775 & 75364 \\
\hline $5 / 15 / 2020$ & 90 & 1361522 & 82119 \\
\hline & & & \\
\hline
\end{tabular}

Table 5: Total number of confirmed cases of COVID-19 and deaths in USA 


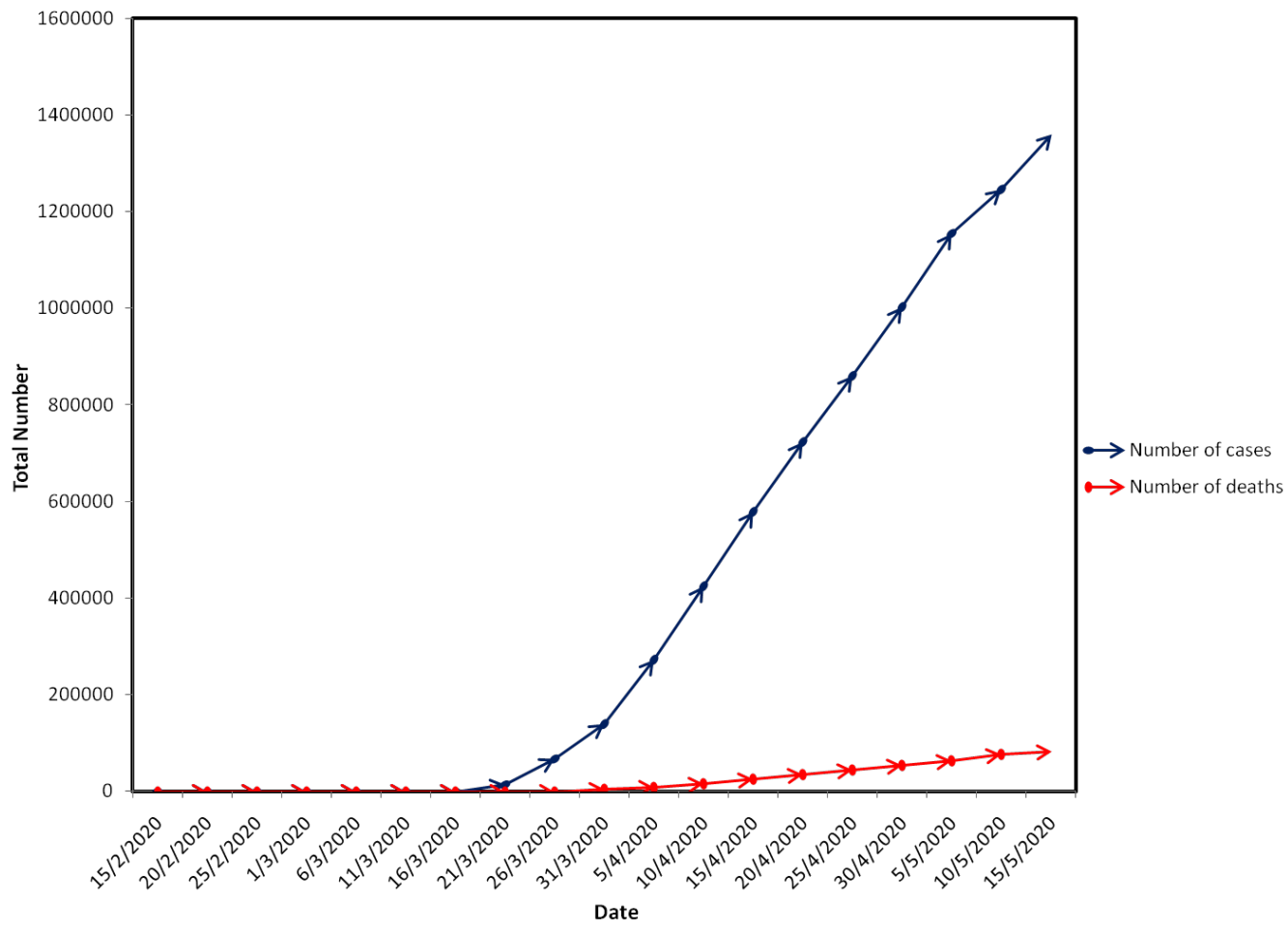

Figure 7: Reported cases of COVID-19 and deaths in USA 
On March 13, the President Donald Trump declared a US national emergency and two days later, the CDC issued an advisory to not holding or attending gatherings of more than 50 people, including concerts, festivals, conferences, sporting events and weddings for eight weeks. The following day, President Trump advised citizens to avoid groups of more than 10. On March 17 the people in Northern California were ordered to "shelter in place" for three weeks, meaning the residents had to remain at home unless going out for an essential purpose, or exercising outdoors. On March 30, more states issued stay-at-home directives including Virginia, Maryland and Washington, D.C., Kansas and North Carolina, at least 265 million Americans were being urged to stay home. Fig 7 shows that the number of confirmed cases keep going at a high rate in the USA which can be attributed to various reasons. It can be deduced that US government was reluctant initially and did not impose the strict preventive measures, as a result a high number of cases and fatalities were reported in the country.

\subsection{Analysis of COVID-19 outbreak in India}

India reported the first case of COVID-19 in Kerala state on January 30, two more cases were reported by 3 February, 2020. No remarkable increase in the number of cases was recorded till the end of February. On March 3, the government stopped issuing of new visas and on March 13, all the visas, previously issued, were suspended except for diplomatic and other official visas. On March 4, 22 new cases were reported including 14 infected cases from a tourist group from Italy. The outbreak intensified during March and several confirmed cases were identified all over the country. Most of the infected cases reported so far had a travel record to affected countries. The confirmed cases crossed 1,000 on $28 \mathrm{March}$, 10,000 on 14 April and 30,000 on 29 April. The day wise total number of cases has been presented in the Table 6 , the day one was considered on 2/15/2020 [18]. By using the data of Table 6 , we graphically visualize the outbreak graphically in Fig. 8. 


\begin{tabular}{|l|l|l|l|}
\hline Date & No. of Days & Total Confirmed Cases Total Deaths \\
\hline $2 / 15 / 2020$ & 1 & 3 & 0 \\
\hline $2 / 20 / 2020$ & 5 & 3 & 0 \\
\hline $2 / 25 / 2020$ & 10 & 3 & 0 \\
\hline $3 / 1 / 2020$ & 15 & 3 & 0 \\
\hline $3 / 6 / 2020$ & 20 & 31 & 0 \\
\hline $3 / 11 / 2020$ & 25 & 60 & 0 \\
\hline $3 / 16 / 2020$ & 30 & 114 & 2 \\
\hline $3 / 21 / 2020$ & 35 & 283 & 4 \\
\hline $3 / 26 / 2020$ & 40 & 649 & 13 \\
\hline $3 / 31 / 2020$ & 45 & 1251 & 32 \\
\hline $4 / 5 / 2020$ & 50 & 3374 & 77 \\
\hline $4 / 10 / 2020$ & 55 & 6412 & 199 \\
\hline $4 / 15 / 2020$ & 60 & 11439 & 377 \\
\hline $4 / 20 / 2020$ & 65 & 17265 & 543 \\
\hline $4 / 25 / 2020$ & 70 & 24506 & 775 \\
\hline $4 / 30 / 2020$ & 75 & 33050 & 1074 \\
\hline $5 / 5 / 2020$ & 80 & 46433 & 1568 \\
\hline $5 / 10 / 2020$ & 85 & 62639 & 2109 \\
\hline $5 / 15 / 2020$ & 90 & 81970 & 2649 \\
\hline & & & \\
\hline
\end{tabular}

Table 6: Total number of confirmed cases of COVID-19 and deaths in India 


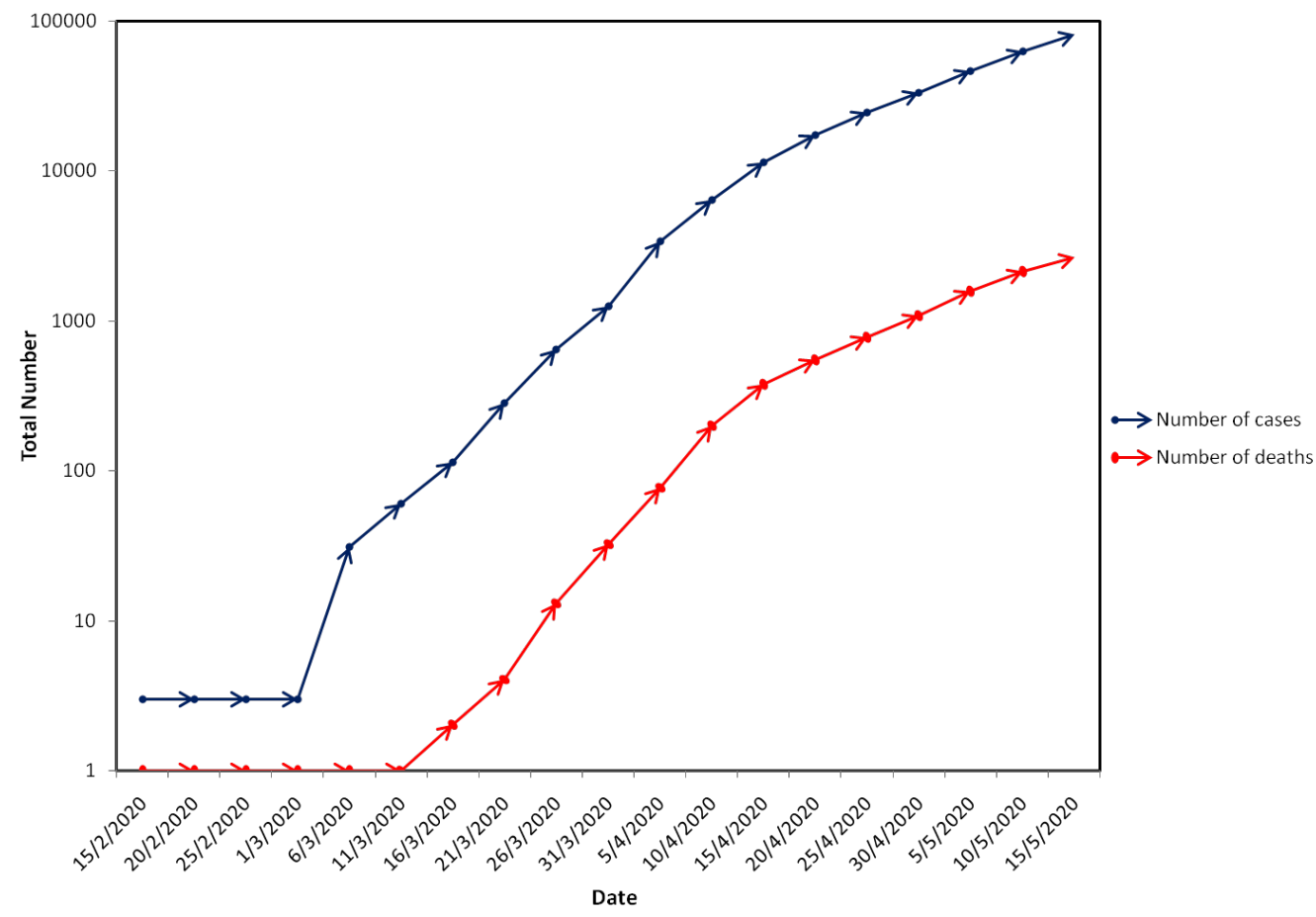

Figure 8: Reported cases of COVID-19 and deaths in India 
The local governments in India responded early to the epidemic and as on March 15 several states including Delhi, Punjab, Karnataka and Himachal Pradesh declared the closure of all the educational institutions till March 31. On March 17, Indian Government issued an advisory, urging to all Indian states to adopt the strategy of social distancing as preventive measures for COVID-19 till 31 March. On 22 March, the Prime Minister Narendra Modi announced for a 14-hour voluntary public curfew and on March 24, declared a nationwide lockdown for 21 days, affecting the entire 1.3 billion population of India. The Fig. 8 shows that the outbreak was under control due to the preventive measures implemented by the government. On April 14, the prime minister announced the extension of the ongoing nationwide lockdown till 3 May. The lockdown measures yielded positively as of 27 April the states of Arunachal Pradesh, Sikkim, Manipur, Nagaland, Goa and Tripura had been announced as "COVID-19 Free" with zero active cases. On 1st of May the lockdown was further extended in the whole country by two more weeks till 17 May. It can be concluded from the Fig. 8 was able to control the epidemics spread due to the effectively and timely implementation of strict preventive measures.

\subsection{A comparative study of COVID-19 outbreak in Italy, UK, USA and India}

To verify the results of our model, we compare the data of total number of confirmed cases in italy, UK, USA and India given in Tables 3, 4, 5, 6 respectively. The impact of corona preventive measures in all these countries can be observed and analyzed in the following graph: 


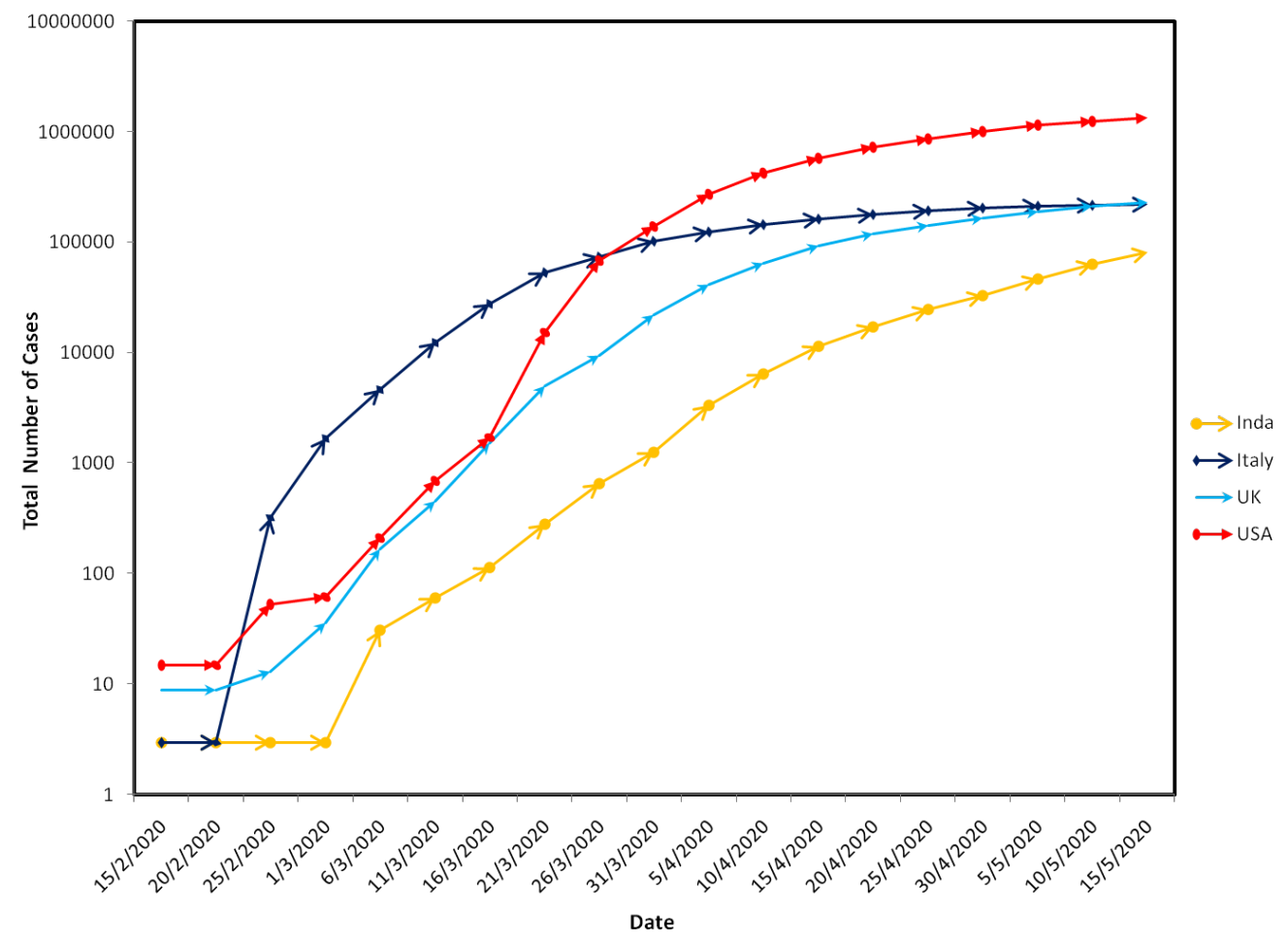

Figure 9: Reported cases of COVID-19 in Italy, UK, USA and India

Fig. 9 shows comparative COVID-19 outbreak in four countries namely, India, Italy, USA and UK. It can be clearly observed that the corona preventive measures played a significant role in controlling the outbreak. In the case of Italy, the epidemic curve was flatten after the few weeks of implementation of preventive measures/lockdown. In India, the epidemic spread is still under control due to the effective and timely implementation of nationwide lockdown. The UK and USA governments were hesitant earlier to take any hard steps such as lockdown, hence the epidemic spread at rapid pace, making them the two most effective countries, as shown in Fig. 9.

\subsection{Substantiation the results of our epidemic model during un- lockdown phase of India}

In India there was complete lockdown, from 22 March, 2020 to 17 May, consequently the rate of spreading of coronavirus disease remained very low in this time-frame as shown in Subsection 4.5. But after mid-May the Indian government gave some relaxation in lockdown; therefore, the quantity of patients increases in masses. Moreover, after 20 May the quantity of patients raised to more than 5,000 every day and to the end of May, 2020 this number increment more than 7,000 every day. Indian government gave more unwinding in June than May and the result was same as in May the number of patients reached 8,000 to 18,000 per 
day to the end of June, 2020. Moreover, this number of patients increased up to 70,000 per day in the end of July, 2020. And this number was around 90,000 in the end of August-September, 2020. Along these lines, we can say that the value of the parameter of our model is so useful to forecast the coronavirus disease. In the following Table 7 and Fig 10, we present entire dynamical behavior of COVID-19 during unlockdown phase of India for the data from 25 May, 2020 to 22 October, 2020 [18]. We observe that total number of cases increased rapidly when the Indian government opened all activities that were prohibited earlier during lockdown. At this stage also, result of our model are fitted well which states that the total number of corona infected patients increased when we decrease the value of corona preventive measures $\mu$.

\begin{tabular}{|l|l|l|}
\hline Date & Total Confirmed Cases Total Deaths \\
\hline $25 / 5 / 2020$ & 138845 & 4021 \\
\hline $4 / 6 / 2020$ & 216919 & 6075 \\
\hline $14 / 6 / 2020$ & 320922 & 9195 \\
\hline $24 / 6 / 2020$ & 456183 & 14476 \\
\hline $4 / 7 / 2020$ & 648315 & 18655 \\
\hline $14 / 7 / 2020$ & 906752 & 23727 \\
\hline $24 / 7 / 2020$ & 1287945 & 30601 \\
\hline $3 / 8 / 2020$ & 1803695 & 38135 \\
\hline $13 / 8 / 2020$ & 2396637 & 47033 \\
\hline $23 / 8 / 2020$ & 3044940 & 56706 \\
\hline $2 / 9 / 2020$ & 3769523 & 66333 \\
\hline $12 / 9 / 2020$ & 4659984 & 77472 \\
\hline $22 / 9 / 2020$ & 5562663 & 88935 \\
\hline $2 / 10 / 2020$ & 6394086 & 99773 \\
\hline $12 / 10 / 2020$ & 7120538 & 109150 \\
\hline $22 / 10 / 2020$ & 7906946 & 116616 \\
\hline & & \\
\hline
\end{tabular}

Table 7: Total number of confirmed cases of COVID-19 and deaths during unlockdown phase of India 


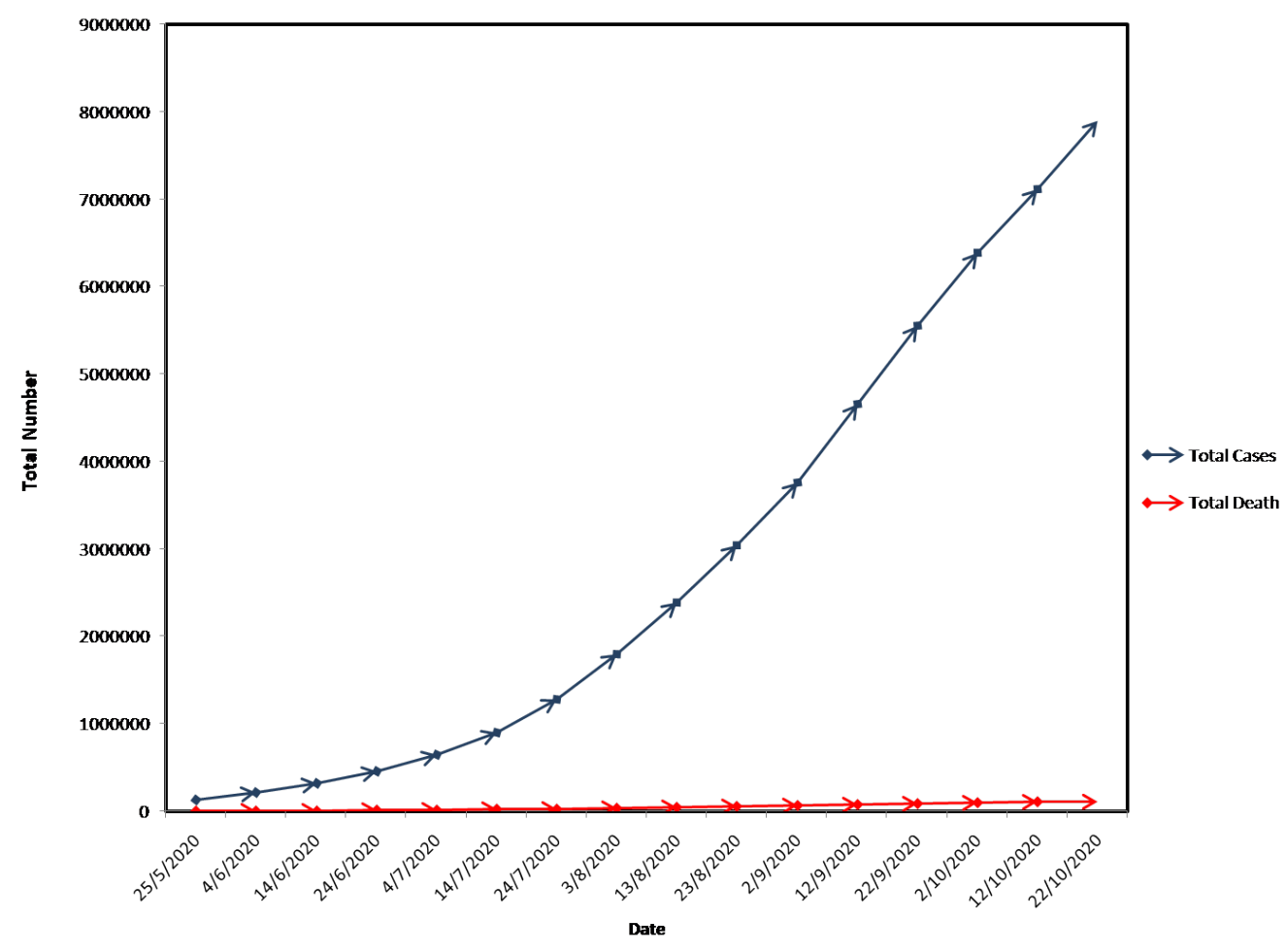

Figure 10: Reported cases of COVID-19 during unlockdown phase of India

\section{Discussion and conclusion}

In the present article, we have employed a novel epidemic model to study the dynamics of COVID19. Our model describes the whole impact of corona preventive measures on the spread of epidemics with the help of time series plot and bifurcation diagrams. The epidemic Model 2 demonstrates that the outbreak of COVID-19 depends on the corona preventive measures adopted by a government. Moreover, in this study, the data of outbreak in five most affected countries have been used to prove the validity of our model. The USA and UK had not imposed any strict preventive measures which resulted in a very high number of total cases as predicted by our model. In China and Italy stringent preventive measures were adopted on later stage and as a result the epidemic curve was flatten within few weeks of implementation of the measures (see Figs. 4 and 5). India imposed a countrywide lockdown on early stage which prevented the spread of epidemic at higher rate. But when Indian government gave some relaxation in lockdown, the coronavirus disease started to spread at higher rate as explained in Subsection 4.7 .

From the above description and discussion, we find that the resulting evolution of the corona infected population depends strongly on the value of the corona preventive measures $(\mu)$ adopted by any government. The main findings of our approach are as follows: 
- For $\mu=100 \%$, the infected population sequence tends to the limit value 0 which means that coronavirus diseases can be eradicated within 60 days by imposing stringent corona preventive measures strictly (shown by magenta line in Fig. 1) . But due to economic point of view, the implementation of $100 \%$ mitigation measures is impossible for any government.

- For $100 \%>\mu \geq 34 \%$, the infected population sequence converges to a stable fixed value (see Columns 5, 6 and 7 Table 1) which imply that the value of infected population remains fixed within 50 days after the implementation of $100 \%>\mu \geq 34 \%$ corona preventive measures as demonstrated by Figs. 1 and 3 .

- The sequence of infected population displays a periodic behavior for $34 \%>$ $\mu>28 \%$ with a period which depends on the value of parameter $\mu$. As we decrease $\mu$ through $34 \%$, firstly, an oscillation between a maximum and a minimum value of infected population (period 2), then an oscillation between 4 different extreme values (period 4) subsequently oscillations with period 8 so on exists in the system (see Figs. 1 and 3).

- For $\mu<28 \%$, the sequence is neither regular nor periodic anymore which reflects the chaotic behavior of the system. Thus the dynamics of COVID-19 follow a period-doubling as here system moves from order to chaos.

- Hence, from our study it can be concluded that the presented model is precise in determining the effect of preventive measures on the outbreak of COVID-19. It suggests a appropriate value of corona preventive measures $(\mu)$ to control the coronavirus disease and eradicate it from the country. Our approach might be useful for such type of epidemic outbreaks.

Conflict of interest: The authors declare that there is no conflict of interest regarding the publication of this article.

\section{References}

[1] Abdo M.S., Shah K., Wahash H. A., Panchal S.K. On a comprehensive model of the novel coronavirus (COVID-19) under Mittag-Leffler derivative. Chaos, Solitons \& Fractals (2020), doi: https://doi.org/10.1016/j.chaos. 2020.109867.

[2] Bhadra A. Time Series Analysis for Nonlinear Dynamical Systems with Applications to Modeling of Infectious Diseases, PhD diss., 2010.

[3] Biswas M.H.A., Haque M.M. Nonlinear Dynamical Systems in Modeling and Control of Infectious Disease. In: Pinelas S., Dol Z., Dol O., Kloeden P. (eds) Differential and Difference Equations with Applications. ICDDEA 2015. Springer Proceedings in Mathematics \& Statistics, vol 164. Springer, Cham., 2016. 
A novel epidemic model to analyze and control the chaotic behavior ...

[4] Brandenburg A. Quadratic growth during the 2019 novel coronavirus epidemic. arXiv, 2020. Preprint at: http://arxiv.org/abs/2002.03638.

[5] Chan J.F., Yuan S., Kok K., To K.K., Chu H., Yang J., et al. A familial cluster of pneumonia associated with the 2019 novel coronavirus indicating person-to-person transmission: a study of a family cluster. Lancet,395(10223), 2020, 514-523.

[6] Chowell G. Fitting dynamic models to epidemic outbreaks with quantified uncertainty: A primer for parameter uncertainty, identifiability, and forecasts. Infect Dis Model., 2(3), 2017, 379-398.

[7] Chowell G., Luo R., Sun K., Roosa K., Tariq A., Viboud C. Real-time forecasting of epidemic trajectories using computational dynamic ensembles. Epidemics, 30, 2020, 100379.

[8] Chowell G., Tariq A., Hyman J.M. A novel sub-epidemic modeling framework for shortterm forecasting epidemic waves. BMC Med., 17(1), 2019, 1-18.

[9] Giovanetti M., Benvenuto D., Angeletti S., Ciccozzi M. The first two cases of 2019-nCoV in Italy: where they come from? J Med Virol. 2020, 14. https: //doi.org/10.1002/jmv.25699 [Epub ahead of print].

[10] Gorbalenya A.E., Baker S.C., Baric R.S. de Groot R.J., Drosten C., Gulyaeva A.A., et al. Severe acute respiratory syndrome-related coronavirus: the species and its viruses - a statement of the coronavirus study group. bioRxiv 2020,120. doi:10.1101/2020.02.07.937862.

[11] Kucharski A.J., Russell T.W., Diamond C., Liu Y., Edmunds J., Funk S., et al. Early dynamics of transmission and control of COVID-19: a mathematical modelling study. Lancet Infect Dis., 2020. doi:10.1016/S1473-3099(20) $30144-4$.

[12] Li L., Jin Z., Yuan S., Wang K., Medvinsky, A.B., Li B.L. Nonlinear Dynamics in Epidemic Systems. Hindawi Publishing Corporation Discrete Dynamics in Nature and Society, Volume 2015, Article ID 703695, 1 page http://dx.doi.org/10.1155/2015/703695.

[13] Li Q., Guan X., Wu P., Wang X., Zhou L., Tong Y., et al. Early transmission dynamics in Wuhan, China, of novel coronavirus-infected pneumonia. N Engl J Med, 2020. https://doi.org/10.1056/NEJMoa2001316.

[14] Lorenz E.N. Deterministic nonperiodic flows. J. Atmos. Sci., 20, 1963, 130141.

[15] Mandal M., Jana S., Nandi S.K., Khatua A., Adak S., Kar T.K. A model based study on the dynamics of COVID-19: Prediction and control. Chaos, Solitons \& Fractals (2020), doi: https://doi.org/10.1016/j.chaos. 2020.109889. 
[16] May R. Simple mathematical models with very complicated dynamics. Nature, 261, 1976, 459-475.

[17] Olsen L.F., Truty G.L., Schaffer W.M. Oscillations and chaos in epidemics: A nonlinear dynamic study of six childhood diseases in Copenhagen, Denmark. Theoretical Population Biology, 33(3), 1988, 344-370. doi:10.1016/ $0040-5809$ (88) 90019-6.

[18] Organization, W. H . Coronavirus disease 2019 (COVID-19) situation reports. https://www.who.int/emergencies/diseases/ novel-coronavirus-2019/situation-reports/

[19] Organization W.H. Coronavirus disease 2019 (COVID19) situation report - 68. https://www.who.int/docs/ default-source/coronaviruse/situation-reports/ 20200328-sitrep-68-covid-19.pdf?sfvrsn=384bc74c_8, 28 March 2020.

[20] Organization W.H. Coronavirus disease 2019 (COVID19) situation report - 106. https://www.who.int/docs/ default-source/coronaviruse/situation-reports/ 20200505covid-19-sitrep-106.pdf?sfvrsn=47090f63_2, 5 May 2020.

[21] Organization W.H. Coronavirus disease 2019 (COVID19) situation report - 116. https://www.who.int/docs/ default-source/coronaviruse/situation-reports/ 20200515-covid-19-sitrep-116.pdf?sfvrsn=8dd60956_2, 15 May 2020.

[22] Organization W.H. Director-general's opening remarks at the media briefing on COVID-19 - 11 march 2020. https://www.who.int/dg/speeches/detail/ who-director-general-s-opening-remarks-at-the-media-l briefing-on-covid-19-11-march-2020, 2020.

[23] Organization W.H. Naming the coronavirus disease (COVID-19) and the virus that causes it. https://www.who.int/emergencies/ diseases/novel-coronavirus-2019/technical-guidance/ naming-the-coronavirus-disease-(covid-2019) -and-the-virus-that-causes-it, 2020.

[24] Organization W.H. SARS (severe acute respiratory syndrome). Available at: https://www.who.int/ith/diseases/sars/en/ [Accessed: 29.02.2020].

[25] Organization W.H. Statement on the second meeting of the international health regulations (2005). emergency committee regarding the outbreak of 
A novel epidemic model to analyze and control the chaotic behavior ...

novel coronavirus (2019-ncov). https://www.who.int/news-room/ detail/30-01-2020-statement-on-the-second-meeting-of-1 theinternational-health-regulations-(2005)

-emergency-committee-regarding-the-outbreak-of-novel-1 coronavirus-(2019-ncov), 2020.

[26] Paraskevis D., Kostaki E.G., Magiorkinis G., Panayiotakopoulos G., Sourvinos G., Tsiodras S. Full-genome evolutionary analysis of the novel corona virus (2019-nCoV) rejects the hypothesis of emergence as a result of a recent recombination event. Infect Genet Evol., 79, 2020, 104212.

[27] Roosa K., Lee Y., Luo R., Kirpich A., Rothenberg R., Hyman J.M., et al. Real-time forecasts of the 2019-nCoV epidemic in China from February 5th to February 24th, 2020. Infect Dis Model., 2020.

[28] Tuite A.R., Fisman D.N. Reporting, Epidemic Growth, and Reproduction Numbers for the 2019 Novel Coronavirus (2019-nCoV) Epidemic. Ann Intern Med., 2020.(February):201920.

[29] Verhulst P.F. Recherches mathmatiques sur la loi d'accroissement de la population. [Mathematical Researches into the Law of Population Growth Increase]. Nouveaux Mmoires de l'Acadmie Royale des Sciences et BellesLettres de Bruxelles. 18, 1945, 1-42. Retrieved 18 February 2013.

[30] Ausloos M. Dirickx M. The Logistic Map and the Route to Chaos: From the Beginnings to Modern Applications, Springer-Verlag, Berlin Heidelberg, 2006.

[31] Viboud C., Simonsen L., Chowell G. A generalized-growth model to characterize the early ascending phase of infectious disease outbreaks. Epidemics, $15,2016,27-37$.

[32] Sugihara G., May R.M. Nonlinear forecasting as a way of distinguishing chaos from measurement error in time series. Nature, 344 (6268), , 1990, 734741

[33] Wang C., Horby P.W., Hayden F., Gao G.F. A novel coronavirus outbreak of global health concern. Lancet, 395, 2020, 470473. doi:10.1016/ s0140-6736(20) 30185-9.

[34] Wu J.T, Leung K., Leung G.M. Nowcasting and forecasting the potential domestic and international spread of the 2019-nCoV outbreak originating in Chen et al. Infectious Diseases of Poverty, 9, 2020, 24.

[35] Ying S., Li F., Geng X., Li Z., Du X., Chen H., et al. Spread and control of COVID-19 in China and their associations with population movement, public health emergency measures, and medical resources. medRxiv, 2020. Preprint at: https://www.medrxiv.org/content/10.1101/2020. $02.24 .20027623 \mathrm{v} 1$. 
[36] You C., Deng Y., Hu W., Sun J., Lin Q., Zhou F., et al. Estimation of the Time-Varying Reproduction Number of COVID-19 Outbreak in China. SSRN. 2020. Preprint at: https://ssrn.com/abstract $=3539694$.

[37] Zaki A.M., van Boheemen S., Bestebroer T.M., Osterhaus A.D., Fouchier R.A. Isolation of a novel coronavirus from a man with pneumonia in Saudi Arabia. N Engl J Med, 367(19), 2012, 1814-1820. doi: 10.1056/ ne jmoa1211721.

[38] Zhang S., Diao M., Yu W., Pei L., Lin Z., Chen D. Estimation of the reproductive number of Novel Coronavirus (COVID-19) and the probable outbreak size on the Diamond Princess cruise ship: A data-driven analysis. Int J Infect Dis., 2020.

[39] Zhao S., Cao P., Gao D., Zhuang Z., Chong M.K.C., Cai Y. Epidemic growth and reproduction number for the novel coronavirus disease (COVID-19) outbreak on the Diamond Princess cruise ship from January 20 to February 19, 2020: A preliminary datadriven analysis. SSRN. 2020. Preprint at: https: / / ssrn.com/abstract $=3543150$.

[40] Zhao S., Lin Q., Ran J., Musa S.S., Yang G., Wang W., Lou Y., Gao D., Yang L., He D., Wang M.H. Preliminary estimation of the basic reproduction number of novel coronavirus (2019-nCoV) in China, from 2019 to 2020: A data-driven analysis in the early phase of the outbreak. International Journal of Infectious Diseases, 92, March 2020, 214-217.

[41] Zhao S., Musa S.S., Lin Q., Ran J., Yang G., Wang W., et al. Estimating the unreported number of novel coronavirus (2019-nCoV) cases in China in the first half of January 2020: a data-driven Modelling analysis of the early outbreak. J Clin Med., 2020. https://doi.org/10.3390/jcm9020388. 